\title{
Virtual training and research laboratory of technological pro- cesses of chemical-technological systems
}

\author{
V.A. Nemtinov ${ }^{1, A}$, Y.V. Nemtinova2,A,B, I.M. Manaenkov3,A \\ A Tambov State Technical University \\ в Derzhavin Tambov State University
}

1 ORCID: oooo-ooo3-2917-3610, nemtinov@mail.gaps.tstu.ru
2 ORCID: oooo-ooo1-9047-2535, $\underline{\text { nemtinov@mail.gaps.tstu.ru }}$
3 ORCID: oooo-o003-1494-9404, jnemtinova@hotmail.com

\begin{abstract}
The article examines the issues related to development of methods for creating a virtual training and research laboratory for chemical and technological systems on the example of technological processes of batch production of organic dyes. The vAcademia programming environment is used as the base software environment for the laboratory prototype. Tools of various systems were used to create laboratory elements: two and three-dimensional design systems: SketchUp, AutoCAD, COMPASS-3D; graphic and video editors: Adobe Photoshop, The GIMP, Photoscape, Windows Movie Maker, SONY Vegas Pro; visual modeling tool for discrete dynamic systems SIMUL8; software for working with texts and tables Microsoft Office. The main purposes of the laboratory are to study the processes of chemical and technological systems, to model them using SIMUL8 modeling system, as well as to create a communicative educational environment that facilitates improving quality of education, exchange of opinions, mutual consultation and, thus, formation of network scientific communities.
\end{abstract}

Keywords: virtual laboratory, technological processes of chemical and technological systems, simulation, communicative educational environment.

\section{Introduction}

Currently, development of the information society in Russia, ensuring citizens' accesses to information and integration into the global information space are priority areas. One of these areas includes creation of specialized educational software environments that improve the quality of training of highly qualified specialists and the level of applied research, as well as facilitate scientific network communities.

The first virtual laboratories appeared in the 90 s of the XX century. In a broad sense, by a virtual laboratory we mean a laboratory (educational or scientific space) as an information resource created by means of modern computer technologies and representing digitized versions of objects of a certain thematic purpose in a virtual space [1 - 7].

Today, there are many different virtual worlds, all of which have 6 features that are inherent in all such worlds [3]:

- common space: many users can participate in the world's life at the same time;

- graphical user interface: the space in the world is reflected virtually, and varies from 2D "cartoon" images to more impressive 3D images;

- efficiency: communication takes place in real time;

- interactivity: the world allows participants to change, develop, build or accept content tailored to them;

- permanence: the world exists regardless of whether individual users are in the system; 
- communication / society: the world enables and promotes formation of social groups within the world, such as teams, guilds, clubs, cliques, neighborhoods, communities and so on.

Currently, the concept of "a virtual scientific research laboratory" represents a software and hardware system that allows conducting experiments without direct contact with real equipment or in the absence of such. Thus, virtual laboratories are defined by two different types of software and hardware systems:

- laboratory classroom installation with remote access - remote laboratories;

- software that allows to simulate laboratory experiments - virtual laboratories. When comparing virtual and real labs, the following benefits of virtual labs can be seen:

- there is no need to buy expensive equipment for all kinds of laboratory experiments. As a result of insufficient funding, most laboratories have installed outdated equipment that may not provide accurate results of experiments or distort them and serve as a potential source of danger for students. In addition, there are areas where it is necessary to purchase consumables for the equipment, the prices of which are quite high. Despite the fact that software and hardware are not cheap as well, their wide prevalence and versatility of computer technology compensates for this drawback;

- ability to simulate a wide range of processes, difficult to be conducted in real laboratory conditions;

- safety is another important reason and advantage of using virtual laboratories, especially when working with hazardous materials and high-voltage devices;

- detailed and multi-view presentation (visualization) on the computer. Currently, modern computer technologies allow users to observe dynamics of the processes that are difficult to be distinguished in real life without specialized equipment;

- ability to "scale" the time. This means that a person conducting an experiment or a laboratory work can observe a process that takes place in a very short time (fractions of a second) in slow motion or, on the contrary, accelerate the process that takes place for a long time (lasting for several years), and this, in turn, makes it possible to get insights into the subtleties of the processes;

- due to the fact that simulation of virtual processes is carried out on a computer, it is possible to conduct many experiments with different values of the input parameters required to determine the desired result.

Virtual laboratories are created in order to simulate real laboratory environment and the processes in it, and at the same time to model a learning environment in which students transform their theoretical knowledge into practical knowledge and skills experimentally. Also, virtual laboratories can give students significant virtual sensations, which allow repeating any failed experiment or expand experimental knowledge. In addition to the advantages in obtaining results, the interactive nature of such teaching methods provides an intuitive and pleasant learning environment and interaction with a virtual laboratory [4].

The articles $[5,6]$ present the e-support methods for vocational learning process at three advancement levels, which can be useful for the preparation of staff according to Industry 4.0 concept and Europe 2020 Strategy. The authors present the application of the animation programmes, which are supportive for learning of CNC programming. They compare the way of learning with the use of real panels for the operator, which are the parts of an individual machine and the animation programme. In the article the authors demonstrate didactic stands for e-learning process in the virtual laboratory.

The article [7] discusses the technology of modeling and visualization of three-dimensional virtual consoles using elements of virtual reality. The technology includes the creation of panels with the help of three-dimensional modeling system 3D MAX, stereo visualization, modeling the user impact on the consoles elements, motion simulation of these elements as a result 
of the impact, as well as the creation and calculation of functional circuits. The developed technology allows to perform such tasks as modeling of real consoles of complex dynamic systems and the development of new consoles with their ergonomic study. Interaction with the elements of consoles is implemented in several ways: using a computer mouse, using the virtual hand and by the real hand of the operator in stereo mode using a tracking system and computer gloves. During the interaction, collisions are tracked, and the dynamics of virtual objects is calculated according to their characteristics.There are following supported elements of $3 \mathrm{D}$ consoles: buttons, toggles, switches and regulators. As a result of interaction the control signals to actuators are generated using functional circuits. Specially designed interactive editor allows one to build complex control circuits from an extensive library of function blocks that implement various functions.

The article [8] presents the experience of joint work of the department "Theoretical and Experimental Physics of Nuclear reactors' and educational scientific laboratory, "Scientific Visualization" of the National Research Nuclear University MEPHI in the development of software tools for visual analysis and a visual illustration of the laboratory work and theoretical study devoted to nuclear power plants process. For example, laboratory work on the uranium-water subcritical assembly, which aims the measurement of the spatial distributions of neutron flux density and the courses: "Experimental Nuclear Physics reactors "and" Neutron Transport Theory " are presented. A brief description of the applications developed for visual analysis and illustration and used in their design the scientific visualization complex components is given. Results of visual energy field analysis obtained by the developed software program and the results of visual illustrations are given as examples.

In this regard, this paper deals with the issues of creating a virtual laboratory of processes of chemical and technological systems on the example of technological processes of batch production of organic dyes, designed to improve the quality of training of highly qualified specialists of chemical and technological sphere and the level of applied research. The software of the vAcademia system is used as the main software environment.

\section{2. vAcademia as a means of creating an educational com- municative environment}

Virtual environment vAcademia is an educational three-dimensional virtual world, which in comparison with other virtual worlds has two main advantages [1-4, 9]:

- vAcademia is a specialized world for education, which means that it has everything that is necessary for the teacher and students in the classroom: interactive whiteboards, overhead projectors, pointers, Webcams, survey systems, models of educational objects, etc.;

- vAcademia has an ability to record classes. The result is a 3 D-recording, which is an exact copy of live classes. These recordings can be visited like regular classes, individually or in a group. However, unlike live activities, recordings can be edited. It is possible to alter the class by removing superfluous information, or, on the contrary, by adding new content.

Each user in a virtual environment is represented by his/her virtual image (avatar). It provides an opportunity to conduct training sessions in the form of: lectures; presentations; seminars; workshops; simulations of various processes and case-studies; "round tables"; trainings; educational quests. vAcademia supports classes for groups of up to 50 users at a time. 


\section{Virtual educational and research laboratory of process- es of chemical and technological systems}

The virtual educational and research laboratory for chemical and technological systems is intended for use in the educational process for professional training of specialists of chemical and technological sphere [12 - 13].

Tools of different systems were used to create laboratory elements:

1) two and three-dimensional design systems: SketchUp, AutoCAD, COMPASS-3D;

2) graphics and video editors: Adobe Photoshop, The GIMP, Photoscape, Windows Movie Maker, SONY Vegas Pro;

3) visual simulation tool for dynamic systems STIMUL8;

4) software for working with Microsoft Office tables and text.

The base of equipment, which is located in the virtual laboratory, includes the main and auxiliary equipment for implementation of organic synthesis: apparatuses with agitators, tanks, pumps, etc. [14 - 15].

Figure 1 shows examples of $3 \mathrm{D}$ models created in the three-dimensional modeling system COMPASS-3D.

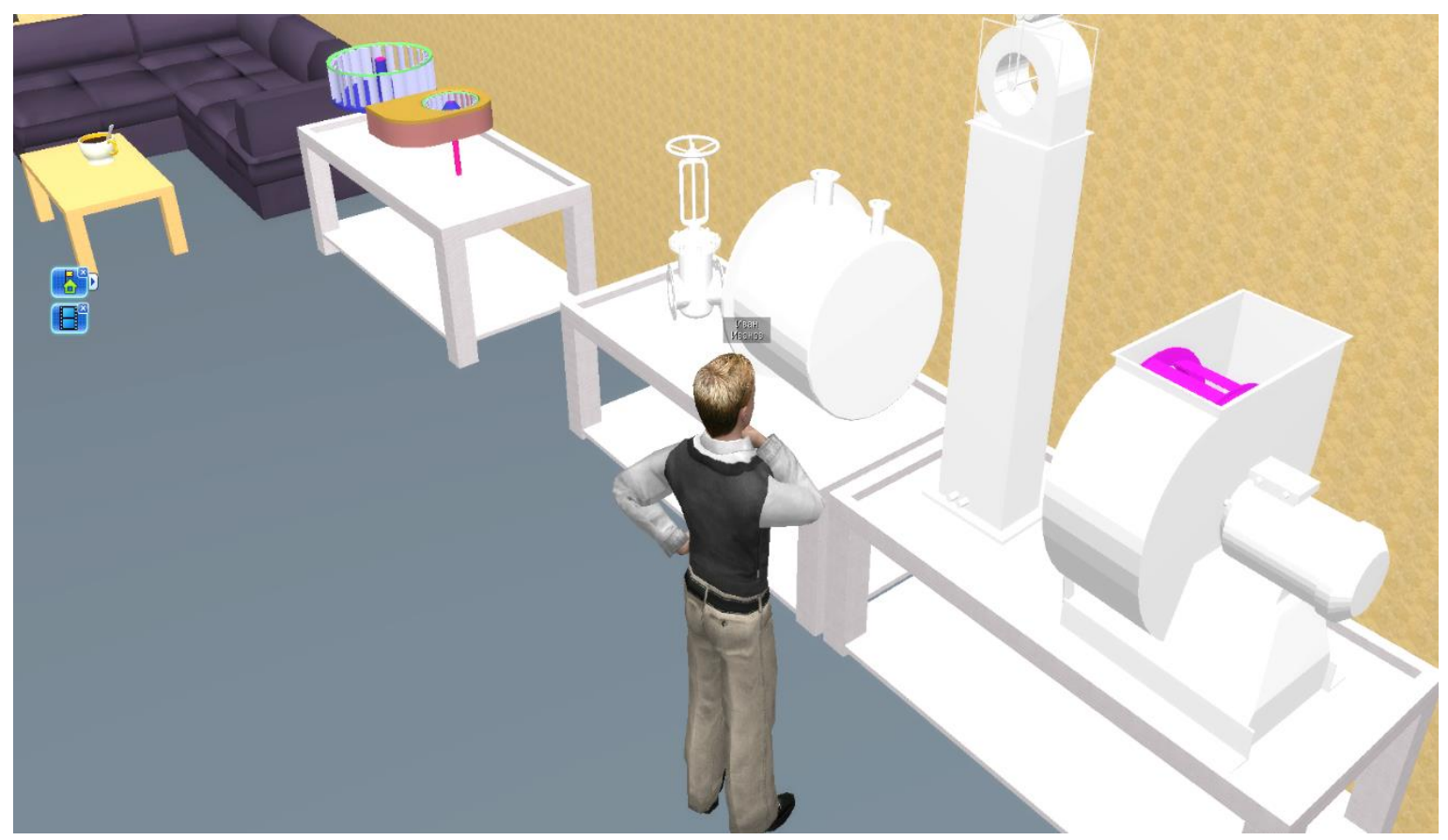

Figure 1. Fragment of technological equipment models in the laboratory

Figure 2 shows a prototype of an engineering unit which is used for studying of organic dyes production. 


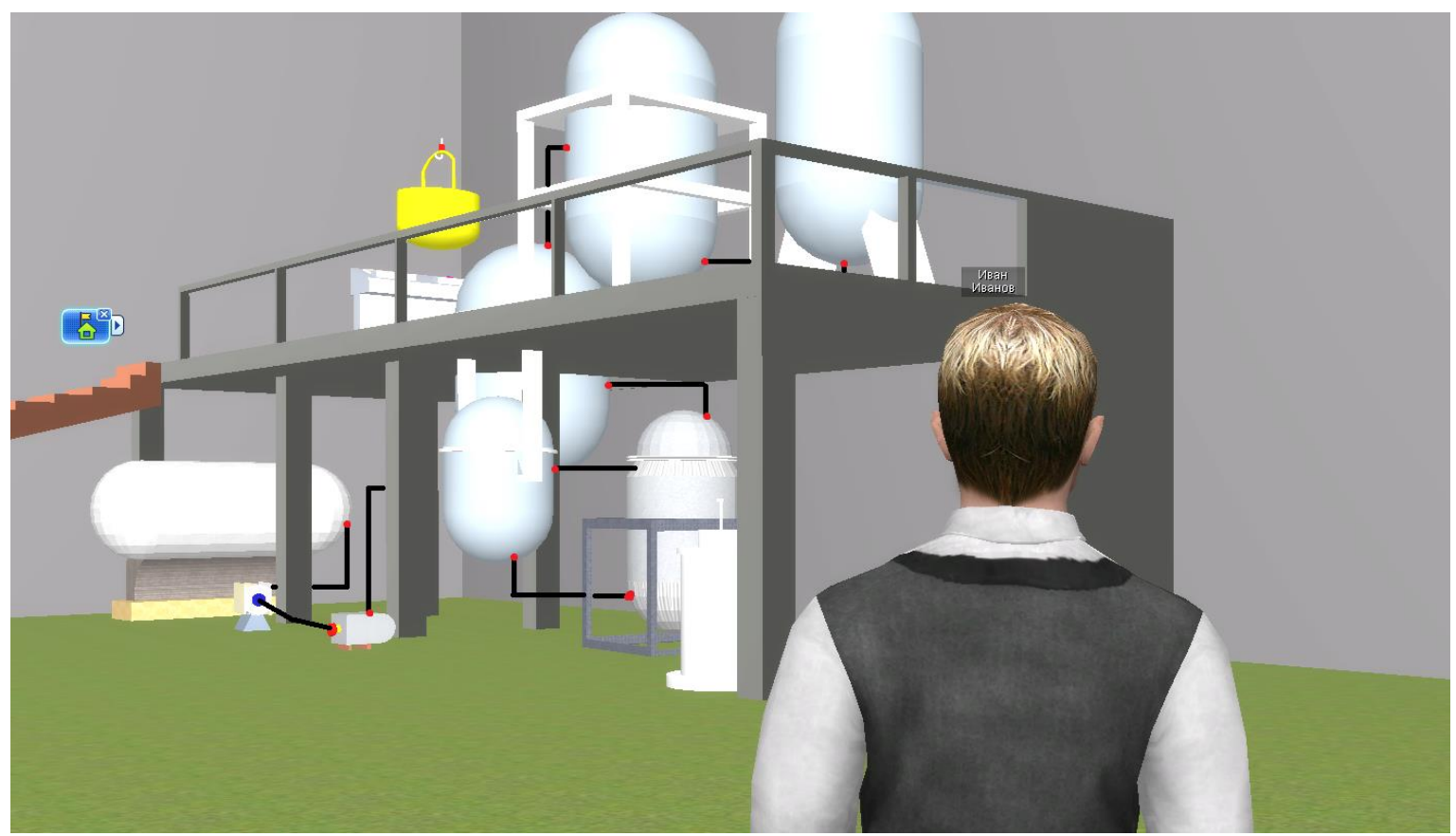

Figure 2. Visualization of an engineering unit

Figure 3 shows the recreation area using both standard $3 \mathrm{D}$ models and computer-aided design systems.

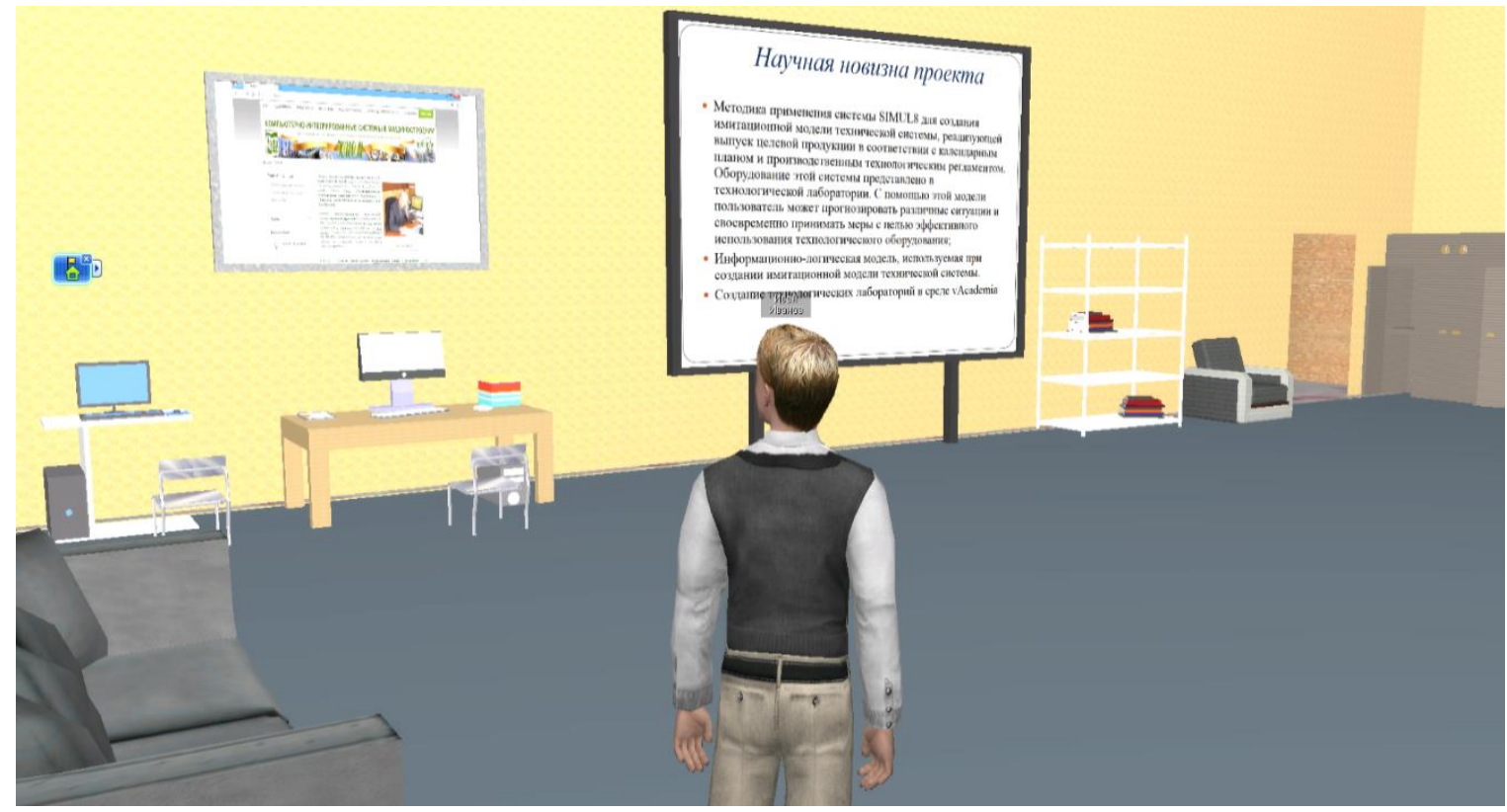

Figure 3. Visualization of a fragment of laboratory's recreation area

For modeling of technological processes of chemical-technological systems on the example of organic dyes production it is expedient to use information-logical models describing the change of the processes components in time. 


\section{Information-logical models of technological processes of organic dyes production}

Currently, many industrial plants are complex dynamic systems characterized by a high level of uncertainty of initial information and complexity of their behavior. To solve many problems associated with management of such systems, as well as to facilitate the work of operators and technologists of chemical and technological systems, simulation can be used [16 $18]$.

In order to investigate technological processes for organic dyes production it is expedient to use the systems which allow imitating real processes [19 - 23].

Computer simulation model is a convenient auxiliary tool for the system analyst who studies chemical and technological objects. The main advantage of simulation is that the expert can answer the question: "what will happen if..." i.e., an experiment with the model helps to develop a research strategy.

The basis for creation of simulation models is information-logical models (ILM) describing conditions of technological processes. In general, a decision support ILM in the study of chemical-technological objects is a combination of data sets and relationships between them recorded in the form of rules. A separate production rule (PR) contained in the knowledge base consists of two parts: the antecedent and the consequent. The antecedent is the premise of the rule (conditional part) and consists of elementary sentences connected by logical bundles "and, or". A consequent (conclusion) includes one or more sentences that express either a certain fact or an indication of a certain action to be performed [14].

Thus, an ILM can be represented by the following tuple [24 -26]:

$$
\mathrm{M}=\langle D, P\rangle, D=\left(d_{1}, \ldots, d_{i}, \ldots, d_{N}\right), \quad P=\left(p_{1}, \ldots, p_{j}, \ldots, p_{S}\right),
$$

where M - operator of an ILM; $d_{1}, \ldots, d_{i}, \ldots, d_{N}$ - sets of ILM data; $p_{1}, \ldots, p_{j}, \ldots, p_{S}$ - sets of rules.

PRs included in the model are constructed by the type: if ... (conditions are met), then ... (implementation of the consequence). A specific type of an ILM for studying chemical and technological object is considered on the example of determining the stage of production depending on the characteristics of raw materials: "characteristics of raw materials and final products" - "production stage", as well as on the example of determining the type of equipment: "production stage" - "equipment". For this, we used a data set on characteristics of raw materials and industrial products $\mathrm{S}_{\text {prod, }}$, data about production stages of the product $S t_{\text {prod }}$ and data about the equipment $O b_{\text {prod }}$ (see table 1-table 3).

$$
\begin{aligned}
& S_{\text {prod }}=\left\{s_{\text {prod }, 1}, \ldots, s_{\text {prod }, i, \ldots,} \boldsymbol{s}_{\text {prod, } I}\right\}, i=\overline{1, I} ;
\end{aligned}
$$

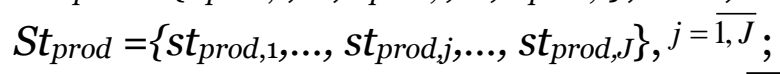

$$
\begin{aligned}
& O b_{\text {prod }}=\left\{o b_{\text {prod }, 1, \ldots,} \text { ob } b_{\text {prod } \left., k, \ldots, o b_{\text {prod }, K}\right\}, k=\overline{1, K}}\right. \text {. }
\end{aligned}
$$

Table 1. Fragment of raw materials characteristics and industrial products

\begin{tabular}{|l|}
\hline Name of indicator \\
\hline$S_{\text {prod }, 1}=$ " slightly alkaline medium reaction" \\
\hline$S_{\text {prod }, 2}=$ " mass concentration of beta-naphthol $243-245 \mathrm{~g} / \mathrm{dm} 3 "$ \\
\hline$S_{\text {prod }, 3}=$ "mass concentration of sodium hydroxide $67-69 \mathrm{~g} / \mathrm{dm} 3 "$ \\
\hline$S_{\text {prod }, 4}=$ " mass concentration of dilute sulfuric acid solution $170-200 \mathrm{~g} / \mathrm{dm} 3 "$ \\
\hline$S_{\text {prod }, 5}=$ " mass fraction of sodium nitrite solution $25-40 \% "$ \\
\hline$S_{\text {prod }, 6}=$ " mass concentration of dilute sulfuric acid solution $170-200 \mathrm{~g} / \mathrm{dm} 3 "$ \\
\hline$S_{\text {prod }, 7}=$ " intake of cooled to 0 ${ }^{\circ}$ C dilute sulfuric acid solution" \\
\hline$S_{\text {prod }, 8=\text { " sulfuric acid excess weight } 30-33 \text { kg } 100 \% \text { sulfuric acid mass" }}$ \\
\hline$S_{\text {prod }, 9=\text { "decreased activity of hydrogen ions is } 6.5-7 \mathrm{pH} \text { units" }}$ \\
\hline$S_{\text {prod, }, 10}=$ " mass fraction of sodium bisulfite $22.5 \% "$ \\
\hline
\end{tabular}




\begin{tabular}{|l|}
\hline$S_{\text {prod,11 }}=$ "mass fraction of the solution is $80-100 \mathrm{~g} / \mathrm{dm} 3 "$ \\
\hline$S_{\text {prod,12 }}=$ "activity index of hydrogen ions of $4.4-4.7 \mathrm{pH}$ units" \\
\hline $\begin{array}{l}S_{\text {prod,13 }}=\text { "reaction of medium of the obtained pigment slurry is clearly alkaline to } \\
\text { brilliant yellow paper (9.0 to } 9.5 \mathrm{pH} \text { units.) }\end{array}$ \\
\hline$S_{\text {prod, }, 14}=$ "compound color - blue" \\
\hline$\ldots$ \\
\hline
\end{tabular}

Table 2. A fragment of the base of production stages

\begin{tabular}{|l|}
\hline Name of the stage \\
\hline$S t_{\text {prod }, 1}=$ "dissolution" \\
\hline$S t_{\text {prod }, 2}=$ "nitrosation" \\
\hline$S t_{\text {prod }, 3}=$ "combination" \\
\hline$\ldots$ \\
\hline
\end{tabular}

Table 3. Fragment of equipment base

\begin{tabular}{|l|}
\hline Name of the unit \\
\hline$O b_{\text {prod }, 1}=$ " reactor for preparation of beta-naphthol sodium salt" \\
\hline$O b_{\text {prod, }, 2}$ " reactor for nitration of beta-naphthol" \\
\hline$O b_{\text {prod, }, 3}=$ " apparatus for combining» \\
\hline$\ldots$ \\
\hline
\end{tabular}

Tables 4 and 5 show examples of rules to define:

- stages of production depending on the characteristics of raw materials and industrial products;

- equipment depending on the production stage.

Table 4. Examples of rules for determining the stage of production depending on characteristics of raw materials and industrial products

\begin{tabular}{|l|l|}
\hline Condition & Consequence \\
\hline$S_{\text {prod }, 1} \& S_{\text {prod }, 2} \& S_{\text {prod }, 3} \& S_{\text {prod }, 4} \& S_{\text {prod }, 5}$ & $S t_{\text {prod }, 1}$ \\
\hline$S_{\text {prod }, 6} \& S_{\text {prod }, 7} \& S_{\text {prod }, 8} \& S_{\text {prod }, 9} \& S_{\text {prod }, 10} \& S_{\text {prod }, 11}$ & $S t_{\text {prod }, 2}$ \\
\hline$S_{\text {prod, }, 12} \& S_{\text {prod }, 13} \& S_{\text {prod }, 14}$ & $S t_{\text {prod }, 3}$ \\
\hline$\ldots$ & $\ldots$ \\
\hline
\end{tabular}

As an example, we give the content of rule 1.

Rule 1: if ( $S_{\text {prod, } 1}=$ "slightly alkaline reaction environment") and ( $S_{\text {prod,2 }}=$ "mass concentration of beta-naphthol 243-245 g/dm3") and ( $S_{\text {prod,3 }}=$ "mass concentration of sodium hydroxide 67$\left.69 \mathrm{~g} / \mathrm{dm}_{3}\right)$ and $\left(S_{\text {prod, } 4}=\right.$ "mass concentration of dilute solution of sulfuric acid 170-200 $\mathrm{g} / \mathrm{dm} 3 ")$ and $\left(S_{\text {prod,5 }}=\right.$ "mass fraction of a solution of sodium nitrite $\left.25-40 \% "\right)$, the production stage of the product $S t_{\text {prod, }}=$ "dissolution".

Table 5. Examples of rules to define equipment depending on the stage of production

\begin{tabular}{|l|l|}
\hline Condition & Consequence \\
\hline$S t_{\text {prod }, 1}$ & $O b_{\text {prod, } 1}$ \\
\hline$S t_{\text {prod }, 2}$ & $O b_{\text {prod }, 2}$ \\
\hline$S t_{\text {prod, }}$ & $O b_{\text {prod }, 3}$ \\
\hline$\ldots$ & $\ldots$ \\
\hline
\end{tabular}

As an example, we give the content of rules 1, 2. 
Rule 1: if $S t_{p r o d, 1}=$ "dissolution", the equipment $O b_{\text {prod }, 1}=$ "reactor for preparation of sodium salt of beta-naphthol".

Rule 2: if $S t_{p r o d, 2}=$ "nitrotyrosine", the equipment $O b_{p r o d, 2}=$ "a reactor for nitration of betanaphthol».

The ILM implemented in the environment for dynamic processes modeling system, for example SIMUL8, will be a tool for studying chemical-technological objects.

In this work, we have proposed the technology for creating simulation models on the example of technological processes of multi-product low-tonnage chemical products, using possibilities of SIMUL8 system for operational management of target production. The main stages of the technology are: formation of a library of technological modes; creation of graphic images of technological schemes of processes, development of a simulation model in SIMUL8 [27 28].

Implementing the proposed technology for development of simulation models of technological processes of chemical production using simulation system of discrete processes SIMUL8, a library of models for production of intermediates and dyes was created, in particular: scarlet pigment $2 \mathrm{C}$, bright red pigment $4 \mathrm{G}$, chrome black pigment $\mathrm{O}$, varnish $\mathrm{PF}-\mathrm{O} 6 \mathrm{O}, 3^{-}$ oxychinaldine-4-carboxylic acid, 3-oxychinophthalon, acryl MEK, etc.

Figure 4 shows the technological scheme for the study of G-salt production, and figure 5 shows the regulations and the simulation model of scarlet pigment $2 \mathrm{~S}$ production.

Thus, the authors have created an educational specialized software environment, which is aimed at improving the quality of training of highly qualified specialists and the level of applied research.

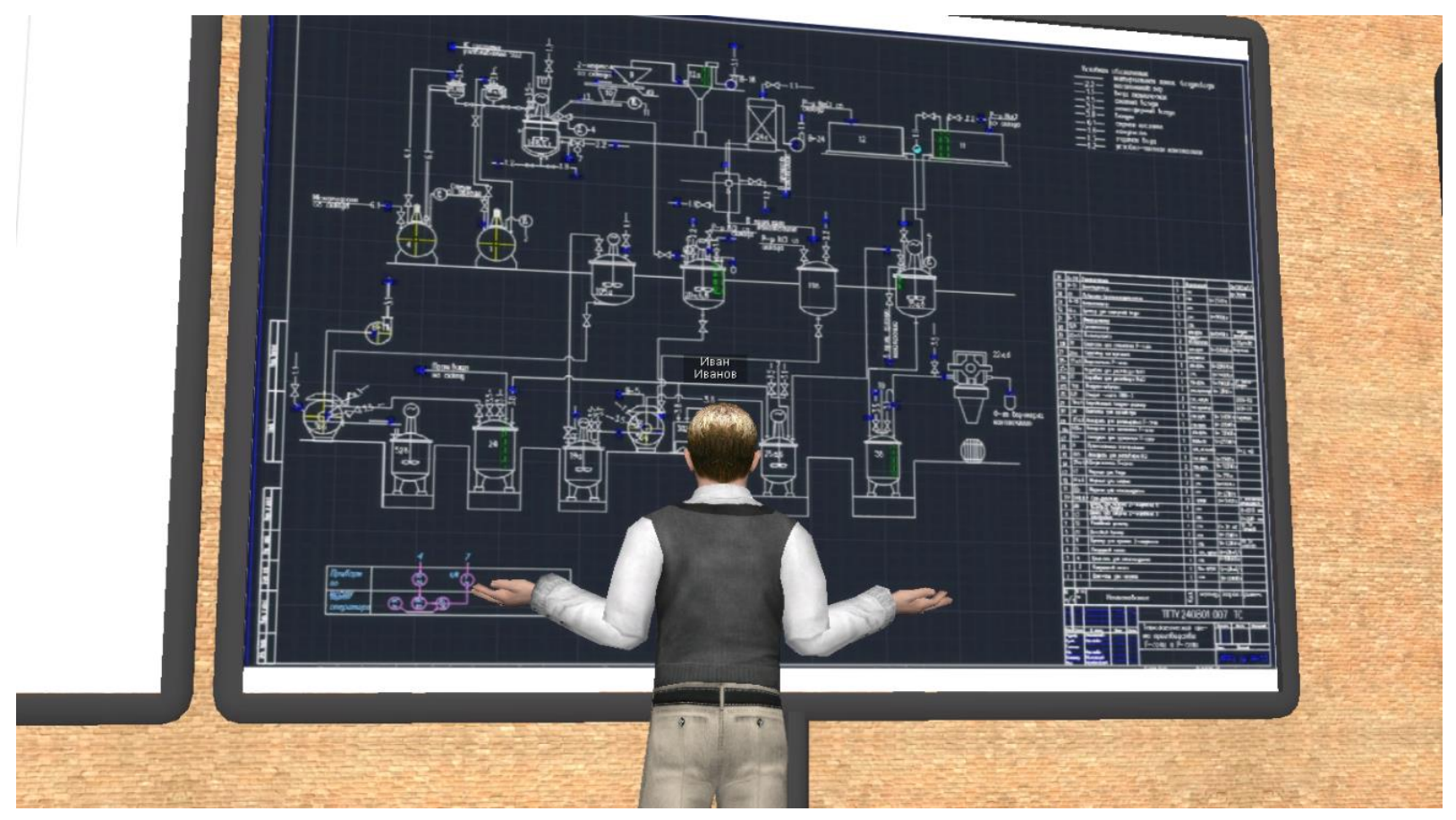

Figure 4. Visualization of a technological scheme of G-salt production 


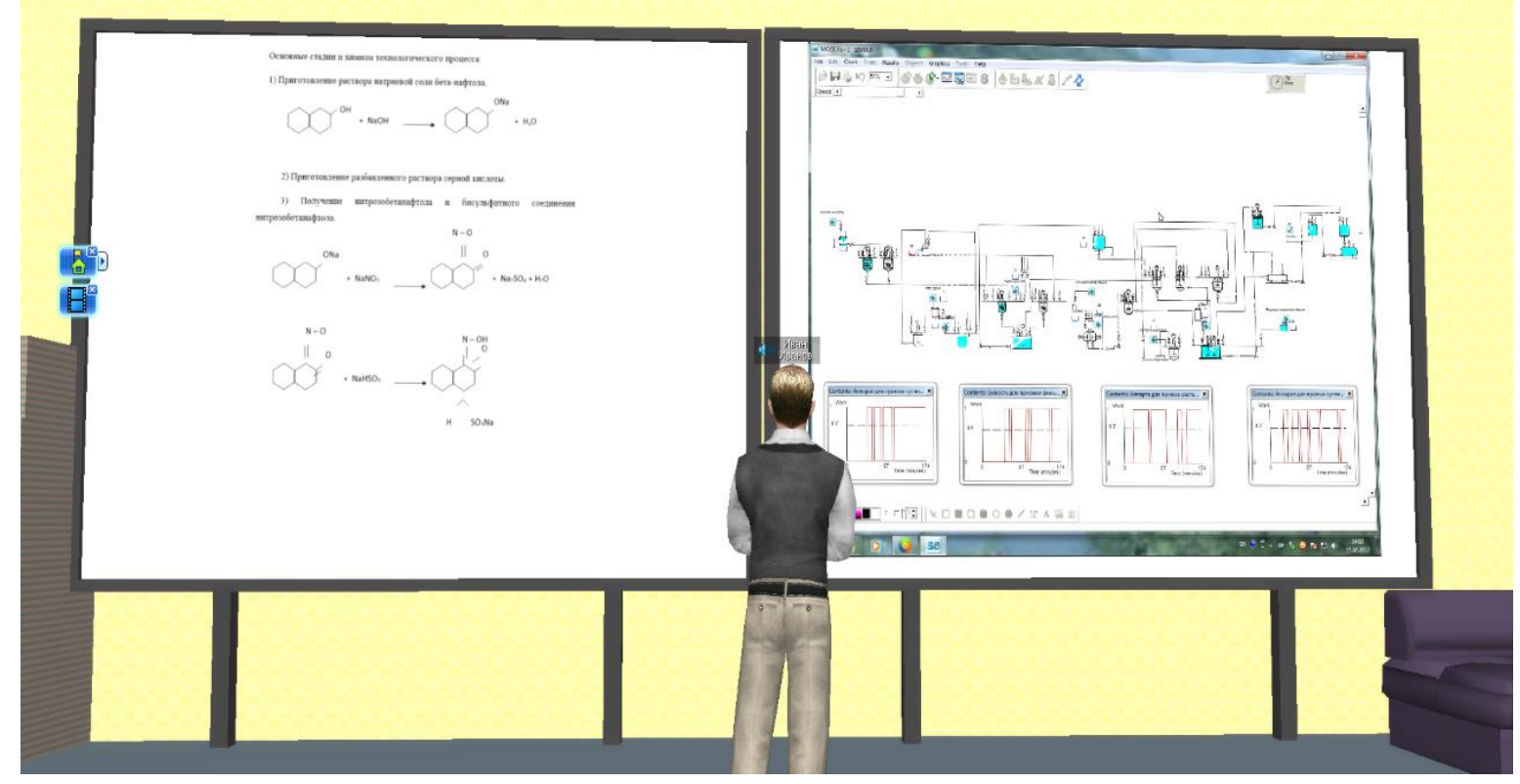

Figure 5. Electronic whiteboard with the description of process parameters and visualization of the simulation model of scarlet pigment $2 \mathrm{~S}$ production

\section{Conclusion}

When conducting research on modeling of chemical and technological systems on the example of organic dyes production, a prototype of a virtual technological laboratory was developed in order to improve the quality of training of highly qualified specialists in chemical and technological areas and the level of applied research. The software environment vAcademia was used to create the laboratory. The items of the laboratory were created with the use of different systems: two and three-dimensional design tools: SketchUp, AutoCAD, KOMPAS-3D, graphic and video editors: Adobe Photoshop, The GIMP, Photoscape, Windows Movie Maker, SONY Vegas Pro; visual modeling tool of dynamical systems SIMUL8; software for working with text and tables Microsoft Office.

\section{Acknowledgements}

The virtual laboratory was created in order to simulate real laboratory environment and its internal processes, educational environment where students and young researchers transform their theoretical knowledge into practical knowledge and skills experimentally, as well as to create a communicative educational environment that provides conditions for improving the quality of education, exchange of opinions and mutual consultation. Thus, the developed information resource will contribute to formation of network scientific communities.

\section{References}

[1] M. Fominykh, E. Prasolova-Forland, L.M. Hokstad and M. Morozov "Repositories of Community Memory as Visualized Activities in 3D Virtual Worlds" 47th Hawaii International Conference on System Sciences (HICSS), Waikoloa, HI, USA, January 6-9, 2014, IEEE, ISBN: 978-1-4799-2504-9/14, P. 678-687.

[2] A. Smorkalov, M. Fominykh and M. Morozov "Stream Processors Texture Generation Model for 3D Virtual Worlds: Learning Tools in vAcademia" 9th International Symposium on Multimedia (ISM), Anaheim, CA, USA, December 9-11, 2013, IEEE, ISBN: 978-0-76955140-1/13, P. 17-24. 
[3] A. Smorkalov, M. Fominykh and M. Morozov "Collaborative Work with Large Amount of Graphical Content in a 3D Virtual World: Evaluation of Learning Tools in vAcademia" 16th International Conference on Interactive Collaborative Learning (ICL), Kazan, Russia, September 25-27, 2013, IEEE, ISBN: 978-1-4799-0153-1, P. 303-312.

[4] "What is a "Virtual World?" [Electronic resource]. URL: http://world2.ru/story/680.html. Access date 24.02.2019.

[5] D. Kowalik, B Rusyn "Innovative Vocational Didactics Aimed at the Preparation of Staff According to Industry 4.0 and Europe 2020" DEStech Transactions on Social Science Education and Human Science. 4th International Conference on Education Reform and Modern Management, Thailand Aug 06-07, pp. 12-17, 2017.

[6] A. Smorkalov, M. Morozov, M. Fominykh "Virtualizing Real-Life Lectures with vAcademia, Kinect, and iPad" Communications in Computer and Information Science vol. 435, part II, pp. 156-161, 2014.

[7] M.V. Mikhaylyuk, M.A. Torgashev "Modeling and visualization of 3d virtual consoles in simulators" Scientific Visualization, vol. 6, no. 4, pp. 50-6o, 2014.

[8] G. Tikhomirov, I. Saldikova, E. Malikova, L. Kuchenkova, V. Pilyugin "NRNU MEPHI experience in development and application of visualization software in nuclear power plants education" Scientific Visualization, vol. 4, no. 2, pp. 57-63, 2012.

[9] "Virtual educational world vAcademia" [Electronic resource] URL: http://vacademia.com/wiki/doku.php. Access date 24.02.2019.

[10] V.A. Nemtinov, A.A. Gorelov, Y.V. Nemtinova, and A.B. Borisenko, "Visualization of a virtual space and time model of an urban development territory" Scientific Visualization, vol. 8, no. 1, pp. 120-132, 2016.

[11] V.A. Nemtinov, A.A. Gorelov, Y.V. Nemtinova, and A.B. Borisenko, "Implementation of technology for creating virtual spatial-temporal models of urban development history" Scientific Visualization, vol. 10, no. 3, pp. 99-107, 2018.

[12] M.N. Krasnyansky, A.I. Popov, A.D. Obukhov "Mathematical Modeling of the Adaptive Control System for Professional Education" Transactions of the Tambov State Technical University, vol. 23, no. 2, pp. 196 -208, 2017.

[13] A.I. Kuptzov, S.A. Kuptzov. R.Z. Xairulin "Development and use of virtual reality technologies in learning processes" Transactions of the Kazan State Technological University, no. 4 (19). pp. 100-101, 2016.

[14] V.G. Mokrozub "Graph structures and relational databases in automated intelligent information systems”. M.: Spectrum Publishing House, 2011. - 108 p.

[15] V.A. Nemtinov, V.G. Mokrozub, P.I. Pahomov, K.V. Nemtinov "Visualization of information space at management of municipal systems" Herald of computer and information technologies. no. 7. pp. 35-39, 2010.

[16] V.A. Nemtinov, S.V. Karpushkin, V.G. Mokrozub, Yu.V. Nemtinova and others. "Virtual modeling of chemical-technological systems. State of the problem": Monograph / Tambov: Publishing House of TSU named after G.R. Derzhavina, 2010. 236 p.

[17] V.A. Nemtinov, S.V. Karpushkin, V.G. Mokrozub, Yu.V. Nemtinova and others. "Methods and algorithms for creating virtual models of chemical-technological schemes": Monograph. Tambov: Publishing House, TSU G.R. Derzhavin, 2011. 282 p.

[18] V.A. Nemtinov, S.V. Karpushkin, V.G. Mokrozub, Yu.V. Nemtinova and others. "The prototype of the virtual model of educational and material resources of the University of chemical technology profile": Monograph. Tambov: Publishing House, TSU G.R. Derzhavina, 2012. - $436 \mathrm{p}$.

[19] A.B. Borisenko, S.V. Karpushkin "Hierarchy of processing equipment configuration design problems for multiproduct chemical plants" Journal of Computer and Systems Sciences International, vol. 53. no. 3. pp. 410-419, 2014. 
[20] A. Borisenko, M. Haidl, S. Gorlatch "A GPU parallelization of branch-and-bound for multiproduct batch plants optimization" The Journal of Supercomputing. vol. 73. no. 2. pp. 639-651, 2017.

[21] A. Borisenko, S. Gorlatch "Comparing GPU-parallelized metaheuristics to branch-andbound for batch plants optimization" The Journal of Supercomputing. pp. 1-13, 2018.

[22] V.A. Nemtinov, A.V. Salushcheva, A.A. Bubnov "Virtual Simulation of Water Treatment Facilities" Transactions of the Tambov State Technical University, vol. 17. no. 2. pp. 445-448, 2011.

[23] V.G. Mokrozub, E.N. Malygin, S.V. Karpushkin "Statement of the Problem of Mathematical and Information Support for the Design of Multi-Product Chemical Plants" Transactions of the Tambov State Technical University, vol. 23 no. 2. C. 252-254, 2017.

[24] V.G. Mokrozub, V.A. Nemtinov, S.Ya. Egorov "Information-logical model of technical facilities and their representation in information systems" Information technology of $C A D / C A M / C A E$, no. 3. pp. 68-73, 2010.

[25] V.G. Mokrozub, E.N. Malygin, S.V. Karpushkin "System Analysis of Decision-Making Processes in the Development of Process Equipment" Transactions of the Tambov State Technical University, vol. 23. no.3. pp. 364-373, 2017.

[26] V.A. Nemtinov, Yu.V. Nemtinova "Using the simulation of dynamic processes for the operational management of industrial production" Chemical Industry Today, no. 7. pp. 4348, 2007.

[27] V.A. Nemtinov, A.M. Manaenkov,V.V. Morozov, E.S. Egorov "Using Internet for support of decision-making in industrial enterprise's management" Applied informatics. no. (28). pp. 8-12, 2010.

[28] V.A. Nemtinov, Yu.V. Nemtinova, D.S. Russkikh "Administrating Control over Production Output Using the System of Modeling Dynamic Processes" Transactions of the Tambov State Technical University, .vol. 13. no. 2. pp. 372-378, 2007. 